\title{
Substantiation and development of technology for a new assortment of combined sour-milk drinks based on bio modified bean raw materials
}

\author{
Nusrat Heydar GURBANOV ${ }^{1}$, Natavan Safar GADIMOVA ${ }^{1 *}$ (D), Rena Islah GURBANOVA, \\ Nazilya Abdul AKHUNDOVA ${ }^{1}$, Aynur Amirkhan BABASHLI ${ }^{1}$
}

\begin{abstract}
Biologically complete combination products have a balanced chemical composition due to the combination of raw materials of animal and vegetable origin. In this aspect, research aimed at the development and creation of dairy and vegetable food of functional purpose are relevant. The article deals with the creation of a combined fermented milk drink such as kefir using milk from sprouted horse bean seeds and natural cow's milk. The possibility of obtaining and applying bean milk from germinated sprouted seeds for the development of the technology of combined fermented milk kefir beverage has been investigated. The mode and technology of obtaining bean milk and kefir drink with it was justified. The inclusion of bean milk from germinated seeds of horse beans, which are completely free from the presence of anti-nutritional components and the action of antitrypsin and hemagglutinin enzymes, is successfully combined with natural milk to develop a new assortment of milk-vegetable sour-milk beverage. Organoleptic evaluation and quality characteristics of acidity showed that the use of milk from beans sprouted seeds instead of part of the milk in the manufacture of kefir drinks, leads to the preparation of samples with improved technological parameters and contributes to the development of healthy milk microflora.
\end{abstract}

Keywords: combined kefir; horse beans; germination of sprouted seeds; bean milk and cow's milk; beverage technology.

Practical Application: Improving the microbiological purity of the raw materials with the use of preliminary short-term hydrothermal treatment.

\section{Introduction}

Biologically high-grade combined products that meet the requirements of the nutrition science are very popular nowadays. Such products have a balanced chemical composition due to a combination of raw material from animal and vegetable origin, simultaneously using expensive milk protein. In this regard, research aimed at the development and creation of dairy-based food products functional focus are actual (Melnikova, 2014; Boyarineva \& Hamagaeva, 2015; Golubeva et al. 2016).

Milk serves as a good basis for creation of combined food products. Usually two methods are used for this purpose:

- adding raw materials of vegetable origin to milk and dairy products;

- adding dairy ingredients to raw materials of vegetable and animal origin.

In solving this issue, vegetable additives are widely used in the dairy industry, as the joint use of dairy and vegetable proteins makes it possible to obtain the perfect composition by amino acid composition in comparison with milk proteins. Herewith, the combined product is simultaneously enriched with biologically active micro components, organic acids and dietary fibers, which ultimately improves its biological value.
In this aspect, the use of germinated (bio activated) seeds of cereal and leguminous crops has one of the leading places in modern food technologies, since the level of above mentioned components is the highest in them. They also contain a high concentration of proteins and biologically valuable fats that preserve essential fatty acids, vitamin E, as well as phospholipids (Weber et al., 2017; Osadchenko et al., 2016; Berezhnaya et al., 2015)

The creation of new products through the combination of functional ingredients also allows correcting the consequences of diseases of civilization.

Thus, Raqibe Karacali and other researchers studied the functional and aromatic properties of kefir obtained using mixtures of cow and soy milk, as well as kefir cultures of Bifidobacterium Longum. It was revealed, that the finished product has high functionality and the agility of formation of aromatic compounds that can be produced in industrial conditions (Karacali et al., 2018).

Greek researchers Mary S. Kalamaki and Apostolos S. Angelidis identified new cultures (Pichia membranifaciens and Candida Zeylanoides) as part of kefir microbiota. Using molecular identification tests, 14 different types of yeast were identified that are present in Greek kefir (Kalamaki \& Angelidis, 2017). 
The viability, physicochemical and sensory properties of kefir microcapsules prepared using maltodextrin /Arabic gum mixtures were studied. At the same time, the determination of moisture, water activity, volumetric density, etc., as well as organoleptic characteristics in the restored samples of kefir microcapsules showed high structural and taste qualities of the manufactured products (Nale et al., 2018). Moreover, the addition of hydrocolloids to kefir before spray drying provides sufficient stability of the powdered drink.

Other authors have shown that the use of innovative ingredients in the development of dairy products simultaneously increases their sales as functional dairy products (Morais et al., 2014).

Thus, the functionality of dairy products becomes more popular if prebiotic ingredients are added to their composition (Cruz et al., 2013; Balthazar et al., 2015). Since the latter simultaneously provide improvements in the nutritional value and quality of manufactured products, such as yogurts, dairy products, cheeses, kefir, etc.

Prebiotics must be resistant to enzymes in the gastrointestinal tract in order to selectively stimulate the growth of beneficial microorganisms and inhibit the development of potentially pathogenic microorganisms (Rolim, 2015). In general, prebiotics significantly improve yield and sensory properties, the texture of dairy products, reduce syneresis, and improve their physicochemical characteristics (Balthazar et al., 2015). The use of prebiotics as a substitute for sugars and fats simultaneously improves the above qualities of these products. Thus, the combination of dairy and vegetable components in the formulations gives advantages in creating the functionality and manufacturability of new products being manufactured.

In the research of Zare et al. (2012), the effect of lentil and bean flour in a volume of $4 \%$ was evaluated on the growth of yogurt and kefir bacteria in the manufacture of dairy products (Zare et al., 2012).

The introduction of legumes and other herbal supplements into dairy products has a prebiotic effect, at the same time stimulates growth and increases viability of probiotic bacteria such as Lactobacillus and Streptococcus Bifidobacterium (Zare et al., 2012; Agil et al., 2013).

\section{Material and methods}

The experiment was conducted with the use of faba beans seeds grown in the southern regions of Azerbaijan of the 2015 harvest season. The seeds were preliminarily subjected to a short hydrothermal treatment and with clearing of the shells.

\subsection{The influence of the germination method on the chemical composition and properties of raw materials}

We propose the method in which during the process of germination the synthesis and activation of enzymes are improved, due to the short-term moisture-heat pretreatment and removal of the peeling before soaking faba beans, because of which the initial chemical composition and the redistribution of amino acids changes in the direction of increasing the essential amino acids. In addition, it transforms macro- and microelements into an easily digestible form. It is known, that in addition to the above-stated merits, in the process of bio activation, i.e. endoenzymatic treatment of the peeled faba bean seeds, the anti-nutritional oligosaccharides (stachyose, ferbascoza, etc.) and tannins are completely removed and disappeared, and the activity level of antitrypsin and hemagglutinin enzymes is reduced to zero. Therefore, relevant to many raw beans, including soybean seed, when germinated by this method the anti-nutritional characteristics completely disappear and they become safer to use (Gurbanov, 2018).

In the composition of germinated seeds, the presence of biologically active components, including whole groups of vitamins, contributes to blood formation, stimulates metabolism, increases immune system, improves digestion, etc. in human organism (Baulina \& Silantyeva, 2014).

To obtain faba bean seeds, ("biopakhla") germinated without a shell, we used a method of treating soybean grain proposed by Russian scientists (Dotsenko \& Skripko, 2005) and modified by us. Their chemical composition, significance, the way of obtaining it and use were reported in detail in our previous publications (Gurbanov et al., 2017a).

\subsection{Development of a combined sour-milk product with a set of specified functional properties}

As the main basic ingredients of the developed product, natural cow milk and legume milk from sprouted seeds with sprouts (village of Windsor, harvest, from southern regions of Azerbaijan in 2015) and fermented yoghurt were used.

According to proposed technology, the seeds of sprouted bean sprouts (Figure 1), which are completely freed from anti-nutritional components, washed and after removing the spoiled ones, they were crushed ( $\mathrm{Dav}=0.8 \mathrm{~mm}$ ) in eight times the amount of water to obtain a thin suspension within 30-40 minutes. At the same time, the $\mathrm{pH}$ of the extract (i.e. water) was maintained at the level of 5.8-5.9 with a temperature $40-50{ }^{\circ} \mathrm{C}$. The resulting suspension was divided into a liquid fraction and an insoluble residue, which was removed. The liquid part (legume milk) contains the following percentages of proteins -3.0 , fat -1.5 , carbohydrate -4.0 mineral substances - more than 2.2 (dry matter - 10.7). Together with natural milk, it was used for the production of milk-vegetable like kefir. The technological scheme for preparing the proposed beverage is shown in Figure 2.

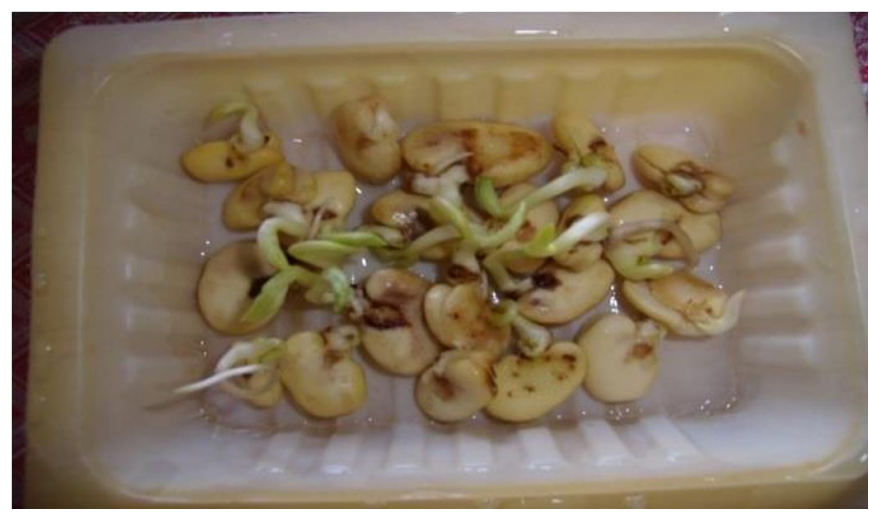

Figure 1. Germinated faba beans seeds germinated in peeled form with its seedlings. 
To characterize the finished products, the commonly used methods were used to measure active acidity during ripening, determine the amount of lactic acid organisms at the end of fermentation, organoleptic evaluation and consistency assessment (Khanturgayev \& Hamagaeva, 2015).

\subsection{Experimental design and statistical analysis}

In selecting the optimal formulation of the sour milk drink, 10 samples of the substrate were prepared. In experimental samples, the composition of dry substances in the bean milk varied from $3 \%$ to $20 \%$, by selecting the ratio of natural and legume milk. The overall results of the research showed that the final product does not meet the necessary requirements with the amount of natural milk in a mixture of less than $50-55 \%$. It was established that the best technological parameters are kefir samples obtained from natural and legume milk in the ratio $70: 30$ and 90:10.

\section{Results and discussion}

The possibility of using the bean milk, obtained from faba bean seeds germinated without shells, in the production of a combined acidophilic (kefir) dairy drink was studied in accordance with the existing traditional technology. For this purpose, the bean milk heated to the temperature of $70-80{ }^{\circ} \mathrm{C}$ was added to the boiling milk at a ratio of 70:30 to the milk normalized for the content of boiling milk. After a good stirring, the mixture was boiled for 3-5 minutes, cooled to the ripening temperature, i.e. to a temperature of $40^{\circ} \mathrm{C}$, and fermented with the introduction of a pure yoghurt culture (lactobacillus acidophilus) for 3\%. Controlling mechanisms were the samples made based on cow's milk with sugar without the use of legume milk.

The prepared samples were thermostatically controlled at the same temperature for 5-6 hours. It was found that the combined cow milk with legume milk improves the ripening process of the drink, i.e. accelerates it in the initial stage of maturation and causes the formation of a clot with acidity in the range of $80-85^{\circ} \mathrm{T}$ (see Table 1 ). As can be seen from Table 1 and Figure 3, the introduction of leguminous milk into the natural milk system reduces the maturation process (i.e. acid formation) by about 1 hour (i.e., 60 minutes) and if it is not stopped (slowed down) by cooling, then it can last up to 8-10 hours of thermostatically controlled above the acid limits characteristic of yoghurt drinks.

Currently, in many countries, when characterizing dairy products, special attention is paid to sensory methods.

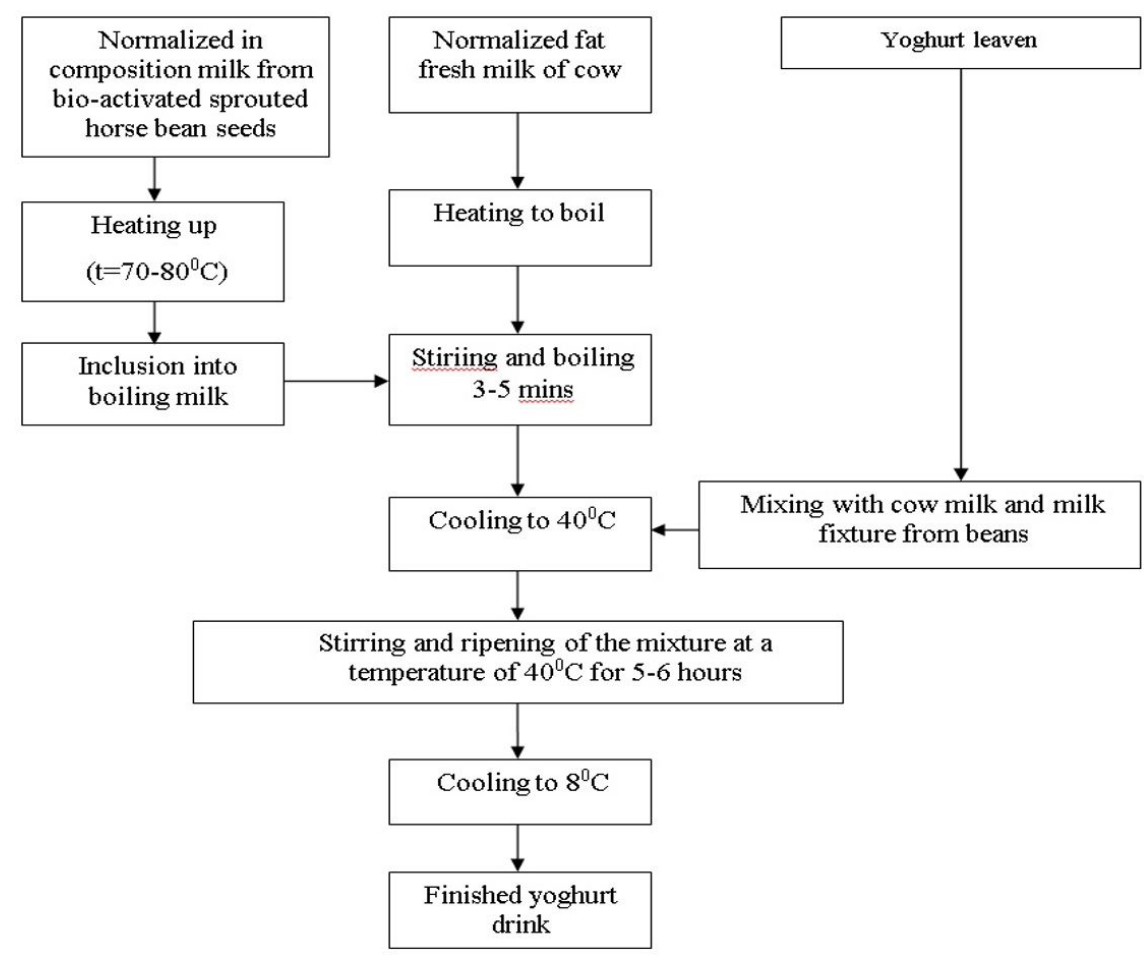

Figure 2. Technological scheme of preparation of a combined yoghurt drink using natural milk and leguminous milk from bio activated seeds in peeled form of faba beans.

Table 1. Change in acidity of yoghurt drink samples during ripening.

\begin{tabular}{|c|c|c|c|c|c|c|c|c|}
\hline \multirow{2}{*}{$\mathrm{N}^{\mathrm{o}}$} & \multirow{2}{*}{ Studied samples } & \multicolumn{7}{|c|}{ Ripening duration, hour } \\
\hline & & 0 & 1 & 2 & 3 & 4 & 5 & 6 \\
\hline \multicolumn{9}{|c|}{ Titrated acidity, ${ }^{0} \mathrm{~T}$} \\
\hline 1. & Drink with a mixture of cow's milk and milk from "biopahly" (sample) & 25 & 45 & 58 & 75 & 72 & 80 & 90 \\
\hline
\end{tabular}


Research in this direction shows that joint comparative studies by physicochemical and sensory methods can give a complete analysis of the picture not only about the quality but also the needs of a product in the consumer market.

Leticia de Paula F. Pinto et al., conducted studies to assess the perception and elucidation of the customer profile for various types of dairy products using two projective methods - the Word Association (WA) and Haires Shopping list (SL), respectively.

The tasks were performed using online surveys, where out of 550 participants, 100 people were interviewed using the WA method, and 450 by SL. It was found that dairy formulations containing casein and lactose demonstrate a lower purchasing power compared to other types of dairy products. This was because they had low sensory qualities and adversely affected the health of consumers. Thus, projective methods, in their opinion, are suitable for assessing quality in the development of new products (Pinto et al., 2018).

Other authors have conducted comparative studies of the physicochemical and sensory indicators of skim goat milk yogurts with the addition of stabilizers and cow skim milk powder to improve the quality of the final product (Bruzantin et al., 2016). The authors used carrageenan and pectin as stabilizers of the dairy system.

The work of Erick A. Esmerino et al. with other authors was aimed at assessing the dynamic sensory profile for three categories of finished dairy products using various temporal methodologies: Temporal Dominance of Sensations (TDS), Progressive Profiling (PP), Temporal Check-All-That-Apply (TCATA) and compared the results (Esmerino et al., 2017a). It was found that the

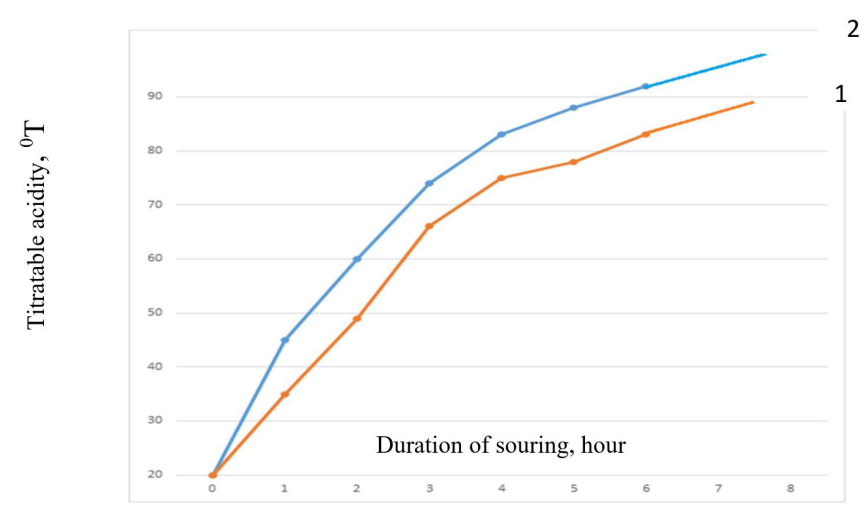

Figure 3. Change in acidity of samples of yoghurt drink during ripening: with a mixture of cow and bean milk (1) and a sugared probe sample (2). various sensory characteristics of these products are mainly related to their commercial identity. To identify differences in intensity, the most sensitive method was the detection of texture changes. The use of PP- is better for products with longer oral treatment than ready-to-eat dairy products. The same authors in another work described the quality of Greek yogurt following the application of three different methodologies: consolidated profiling (PP), Check- All-That-Apply (CATA) and projective matching (PM) to show which one is better (Esmerino et al., 2017b). It is shown that the method of Progressive Profiling (PP) has a significant advantage over others. The experimental universality of this method allows its widespread use in practice. Thus, all this shows the usefulness of using projective methods to understand consumer preferences and opinions about dairy products during their development.

Organoleptic evaluation of prototypes of yoghurt drink in comparison with the control ones showed their best taste qualities on a five-point rating system. Therefore, drinks made with sugar received 3.8 points, and with the addition of legume milk 4.5 points. At the same time, the sour taste of the experimental samples of the drink was masked by a kind of sugary taste of bio-activated beans. In addition, the microbiological analysis of these samples showed that the amount of lactic acid microorganisms at the end of the fermentation corresponds to the required values, i.e. not less than $1 \cdot 10^{7} \mathrm{cfu}$ in $1 \mathrm{~cm}^{3}$ of beverage. In terms of the consistency, in both samples they were comparable, as in milk drinks. All this indicates that the Lactobacillus acidophilus in the presence of legume milk of 30\% develops normally in the milk system and causes the acceleration of the ripening process.

It was of interest to study the changes in acidity and organoleptic parameters of probe and experimental samples of the yoghurt drink during storage at regulated temperatures in cold conditions $\left(4^{\circ} \mathrm{C}\right.$ and $\left.8{ }^{\circ} \mathrm{C}\right)$. The change in the quality of the samples was controlled by the determination of titrated acidity and by an organoleptic route. Storage was carried out up to 5 days.

Acidity is the main physical-chemical indicator by which one can observe changes in the chemical composition of fermented beverages during ripening and storage.

The results of the study showed that during the storage of experimental and probe samples at a temperature of $4{ }^{\circ} \mathrm{C}$ and $8^{\circ} \mathrm{C}$, acidification processes still continued in them (see Table 2 and Figure 4 and 5). However, these processes proceed slowly. At the same time, the acceleration of acidity is even slower in samples made with the inclusion of milk from bio-activated seeds of beans. The organoleptic examination showed that during the

Table 2. Change in acidity of yoghurt drink samples depending on temperature and storage time.

\begin{tabular}{|c|c|c|c|c|c|c|c|}
\hline \multirow{3}{*}{$\mathrm{N}^{\circ}$} & \multirow{3}{*}{ Studied samples } & \multirow{3}{*}{$\begin{array}{c}\text { Storage } \\
\text { temperature, }{ }^{\circ} \mathrm{C}\end{array}$} & \multicolumn{5}{|c|}{ Storage duration, hour } \\
\hline & & & 0 & 12 & 48 & 72 & 120 \\
\hline & & & \multicolumn{5}{|c|}{ Titrated acidity, ${ }^{0} \mathrm{~T}$} \\
\hline 1. & Drink with a mixture of cow's milk and milk from biopahly & +4 & 80 & 90 & 95 & 105 & 110 \\
\hline 2. & Test (their cow's milk with sugar) & +4 & 82 & 85 & 95 & 110 & 120 \\
\hline 3. & Drink with a mixture of cow's milk and milk from biopahly & +8 & 80 & 85 & 95 & 110 & 115 \\
\hline 4. & Test (from cow's milk with sugar) & +8 & 82 & 90 & 105 & 110 & 120 \\
\hline
\end{tabular}




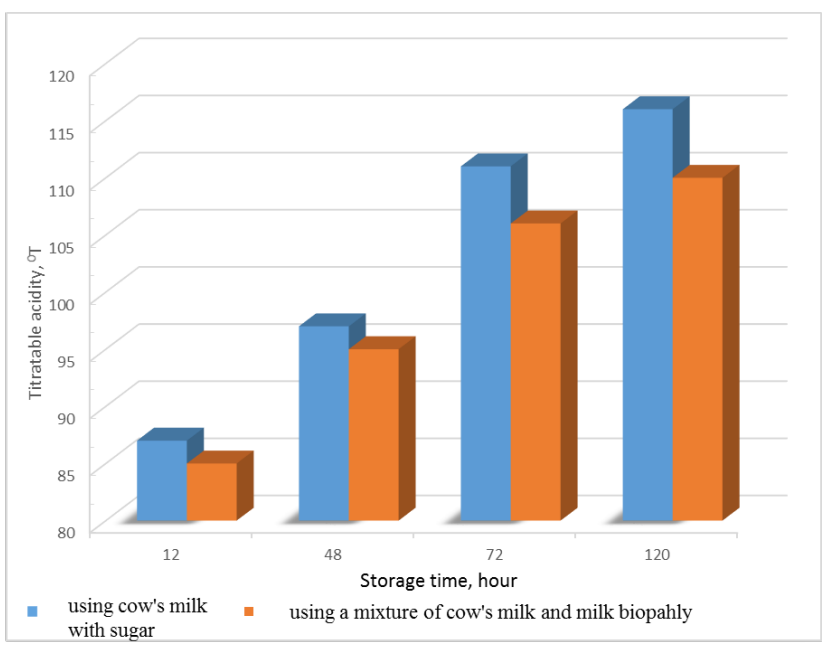

Figure 4. Change in the acidity of yoghurt drink samples during storage at a temperature of $4{ }^{\circ} \mathrm{C}$.

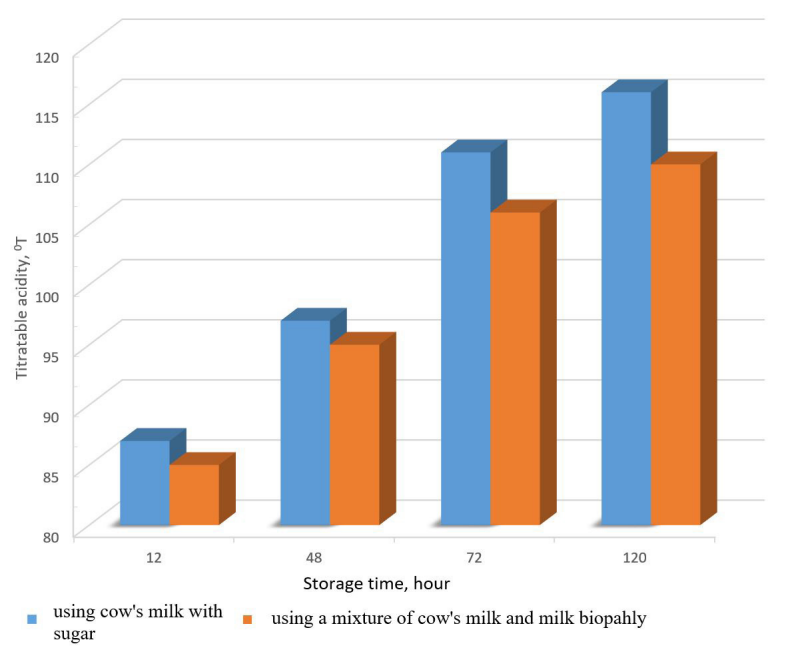

Figure 5. Change in the acidity of yoghurt drink samples during storage at a temperature of $8{ }^{\circ} \mathrm{C}$.

storage in sugared drinks (i.e. probe samples) the liquid serum were isolated. This was not observed in experimental samples. In addition, the sugared probe samples got an even more acidic taste than the experimental ones.

\section{Conclusion}

In a word, the use of so-called milk from bio activated bean seeds without shells instead of some part of milk in production of acidophilic drinks, makes it possible to obtain samples with improved technological parameters, i.e. which differ by the acceleration of acid formation, the improvement of the nutritional value, the stability during the heat treatment of milk, the preservation of the structure of the milk protein system during the storage in cold, and promotes the development of useful lactic microflora. The preservation of the structure and acidity of the prototypes system with a decrease in temperature from $8{ }^{\circ} \mathrm{C}$ to $4{ }^{\circ} \mathrm{C}$ during storage becomes even better, which also prolongs the shelf life.

All this shows that the technology, proposed by us, from bio activated seeds without shells of faba beans from local raw materials, containing flavoring and protein components, is a suitable product (polyfunctional food additive) for the production of combined sour-milk drinks with dietary and curative prophylactic properties.

The results of the study of the acidity of the proposed combined yoghurt drink during storage show that, in addition to these positive qualities, during the shelf life of the standardized indicators for this product remain within the limits of the required GOST R 52092, i.e. within $85-130^{\circ} \mathrm{T}$.

\section{References}

Agil, R., Gliwa, J., Gaget, A., \& Avis, T. (2013). Lentils enhance probiotic growth in yogurt and provide added benefit of antioxidant protection. Food Science and Technology, 50(1), 45-49.

Balthazar, C. F., Gaze, L. V., Silva, H. L. A., Pereira, C. S., Franco, R. M., Conte, C. A. Jr, Freitas, M. Q., \& Silva, A. C. O. (2015). Sensory evaluation of ovine milk yogurt with inulin addition. International Journal of Dairy Technology, 68(2), 281-290. http:// dx.doi.org/10.1111/1471-0307.12189.

Baulina, M. A., \& Silantyeva, L. A. (2014). Development of technology for fermented milk dessert enriched with whey proteins and germinated beans of lentils. Food Industries, 9, 12-14.

Berezhnaya, O. V., Dubtsov, G. G., \& Voyno, L. I. (2015). Wheat sprouts - ingredient for food products. Food Industries, 5, 26-29.

Boyarineva, I. V., \& Hamagaeva, I. S. (2015). Combined dairy products, enriched with cereals. Food Industries, 10, 28-30.

Bruzantin, F. P., Daniel, J. L. P., da Silva, P. P. M., \& Spoto, M. H. F. (2016). Physicochemical and sensory characteristics of fat-free goat milk yogurt with added stabilizers and skim milk powder fortification. Journal of Dairy Science, 99(5), 3316-3324. http://dx.doi.org/10.3168/ jds.2015-10327. PMid:26971159.

Cruz, A. G., Cavalcanti, R. N., Guerreiro, L. M. R., Sant'AnaA, S., Nogueira, L. C., Oliveira, C. A. F., Deliza, R., Cunha, R. L., Faria, J. A. F., \& Bolini, H. M. A. (2013). Developing a prebiotic yogurt: Rheological, physicochemical and microbiological aspects and adequacy of survival analysis methodology. Journal of Food Engineering, 114(3), 323-330. http://dx.doi.org/10.1016/j.jfoodeng.2012.08.018.

Dotsenko, S. M., \& Skripko, O. V. (2005). New soybean technology. Journal of Nutrition and Society, 9, 17.

Esmerino, E. A., Castura, J. C., Ferraz, J. P., Tavares Filho, E. R., Silva, R., Cruz, A. G., Freitas, M. Q., \& Bolini, H. M. A. (2017a). Dynamic profiling of different ready-to-drink fermented dairy products: A comparative study using Temporal Check-All-That-Apply (TCATA), Temporal Dominance of Sensations (TDS) and Progressive Profile (PP). Food Research International, 101, 249-258. http://dx.doi. org/10.1016/j.foodres.2017.09.012. PMid:28941691.

Esmerino, E. A., Tavares Filho, E. R., Thomas Carr, B., Ferraz, J. P., Silva, H. L. A., Pinto, L. P. F., Freitas, M. Q., Cruz, A. G., \& Bolini, H. M. A. (2017b). Consumer-based product characterization using Pivot Profile, Projective Mapping and Check-all-that-apply (CATA): A comparative case with Greek yogurt samples. Food Research International, 99(1), 375-384. http://dx.doi.org/10.1016/j. foodres.2017.06.001. PMid:28784495. 
Golubeva, L. V., Dolmatova, O. I., Pozhidaeva, E. A., Grebenkina, A. G., Zygalova, E. I., \& Medko, J. G. (2016). New fermented milk product with flavoring components of plant origin. Food Industries, 12, 18-20.

Gurbanov, N. H. (2018). The study of microbiological safety of germinated seeds of broad beans in the process of their production and storage. Journal of Advancements in Food Technology, 1(1), 105.

Gurbanov, N. H., Gurbanova, R. I., Magerramova, M. G., \& Iskenderova, M. M. (2017a). The study of changes in general chemical and amino acid composition, the activity of enzymes of peeled horse bean seeds in the process of germination. Works of Azerbaijan Agro University, 3, 45-49.

Gurbanov, N. H., Gurbanova, R. I., Magerramova, M. G., \& Iskenderova, M. M. (2017b). Combined protein-vitamin salad based on sprouted horse bean seeds. "Collection of news" of the National Academy of Sciences of Azerbaijan. Ganja Branch, 4(70), 134-144.

Kalamaki, M. S., \& Angelidis, A. S. (2017). Isolation and molecular identification of yeasts in Greek kefir. International Journal of Dairy Technology, 70(2), 261-268. http://dx.doi.org/10.1111/1471-0307.12329.

Karacali, R., Özdemir, N., \& Çon, A. H. (2018). Aromatic and functional aspects of kefir produced using soya milk and Bifidobacterium species. International Journal of Dairy Technology, 71(4), 921-933. http://dx.doi.org/10.1111/1471-0307.12537.

Khanturgayev, A. G., \& Hamagaeva, I. S. (2015). Development of technology for producing sour-milk beverage "Bifit cedar". Food Industries, 2, 12-14.

Melnikova, E. I. (2014). Lupine milk-plant extract - raw material for functional foods. Food Industries, 5, 70-72.
Morais, E. C., Morais, A. R., Cruz, A. G., \& Bolini, H. M. A. (2014). Development of chocolate dairy dessert with addition of prebiotics and replacement of sucrose with different high- intensity sweeteners. Journal of Dairy Science, 97(5), 2600-2609. http://dx.doi.org/10.3168/ jds.2013-7603. PMid:24612793.

Nale, Z., Tontul, I., Arslan, A. A., Nadeem, H. S., \& Kucukcetin, A. (2018). Microbial viability, physicochemical and sensory properties of kefir microcapsules prepared using maltodextrin/Arabic gum mixes. International Journal of Dairy Technology, 71(1), 61-72. http://dx.doi.org/10.1111/1471-0307.12402.

Osadchenko, I. M., Gorlov, I. F., Mosolova, N. I., Kharchenko, O. V., \& Nikolayev, D. V. (2016). Intensive technology of seeds germination as components for food purposes. Food Industries, 2, 44-46.

Pinto, L. P., Silva, H. L. A., Kuriya, S. P., Macaira, P. M., \& Cyrino Oliveira, F. L. (2018). Understanding perceptions and beliefs about different types of fermented milks through the application of projective techniques: A case study using Haires shopping list and free word association. Journal of Sensory Studies, 33(3), e12326. http://dx.doi. org/10.1111/joss.12326.

Rolim, P. M. (2015). Development of prebiotic food products and health benefits. Food Science and Technology (Campinas), 35(1), 3-10. http://dx.doi.org/10.1590/1678-457X.6546.

Weber A.L., Kazydub N.G., Leonova S.A., \& Giarno M. (2017). Obtaining the biologically active component from germinated beans of beans for the purpose of its subsequent use. Bakery Products, 6, 35-38.

Zare, F., Simpson, B., Champagne, C. P., \& Orsat, V. (2012). Effect of the addition of pulse ingredients to milk on acid production by probiotic and yoghurt starter cultures. Food Science and Technology, 45(2), 155-160. 